Joanna Ludwika Pękala

https://doi.org/10.26881/pwe.2020.49.12

ORCID: 0000-0003-4554-1962

Uniwersytet Warszawski

jpekala@uw.edu.pl

Kamila Wichrowska

ORCID: 0000-0003-3559-9706

Uniwersytet Warszawski

kamila.wichrowska@uw.edu.pl

\title{
The BRIDGING project - citizenship, partnership and holistic development
}

\begin{abstract}
Summary
The aim of the text is to introduce BRIDGING, an international project that involves professionals working in educational institutions (kindergarten, school or crèche), academic and cultural institution from Poland, Portugal, Finland and Belgium ${ }^{1}$. The project aims to improve the quality of practices in early childhood education through participation of children, teachers, cultural and academic staff in artistic projects in public spaces. Crucial part of BRIDGING is to promote various ways of communication of children and adults using the concept of citizenship in the context of holistic approach. Additionally our intention is to introduce the preliminary results of the first Polish part of the BRIDGING project research. The study was conducted to investigate how the project is perceived by kindergarten teachers. Although only the first results are presented here, it is already quite evident what the specific areas of teachers' sense of vocational self-efficacy are. The results show that our respondents value the experiences brought to them by the project. In their opinion BRIDGING gave them an opportunity to acquire knowledge about their city, neighbourhood and the partners' countries. They also stated that the project has improved their skills of using ICT tools and various art techniques.
\end{abstract}

Keywords: BRIDGING project, citizenship, holistic approach, self-efficacy

Słowa kluczowe: projekt BRIDGING, obywatelstwo, podejście holistyczne, poczucie własnej skuteczności

\section{Introduction}

BRIDGING is an international project, taking place within the years 2018-2020, funded by the European Union. The main goal of the project is to improve the quality of practices in early childhood education and care through children's, teachers', caregivers' academics' and

\footnotetext{
1 One institution of each per country; the only exception is Portugal, that is being represented by two educational institutions: a kindergarten and a primary school.
} 
cultural institutions staff's participation in diverse public spaces. It allows them to enhance their local as well as European sense of citizenship through the process of collaboration and communication. That kind of cooperation leads to the development of fresh insights and new ideas (De Rond 2014) as well as promoting cultural sensitivity, self-efficacy, inclusion and expression through different means of communication, such as art, music, architecture, environment, ICT tools.

According to Britannica, citizenship is a "relationship between an individual and a state to which the individual owes allegiance and in turn is entitled to its protection. Citizenship implies the status of freedom with accompanying responsibilities" (britannica.com). The concept of citizenship should be perceived as a dynamic process, related to cultural learning, through which children are engaged in practices impacting on their everyday lives. It helps in developing a strong partnerships to understand and build on children's experiences and work on their well-being. BRIDGING follows an approach that supports children, teachers and families in building a community (Darling-Hammond et al. 2019). European society is becoming more and more diverse. Teachers and caregivers need new skills and approaches to fulfil the requirements of an inclusive classroom. Therefore, the BRIDGING project aims at close collaboration of several institutions within each country and between partner countries, involving: school settings (school, pre-school or crèche), academic institutions and cultural settings. There are several partners from four European countries - Belgium, Finland, Portugal (leader) and Poland - taking part in the project. Close collaboration between different international partners enriches many fields of work and cooperation, e.g. education, arts, architecture, ICT and science. It enables effective operationalization of the educational process, leading to the improvement of the process of professional development and high quality practices (Bove et al. 2018). BRIDGING promotes cooperation and communication between children, their teachers and caregivers and various spaces around the city, e.g. the school, playground, local environment, characteristic buildings, etc. The project gives its participants many opportunities to become more involved and more confident as citizens of their own local communities, their country as well as Europe.

The BRIDGING project is in line with holistic education. Ron Miller describes holistic education as a concept based on the assumption that every student and every person finds identity, meaning and purpose in life via connections to the community, to the natural world, and to the so-called spiritual values, i.e. compassion (Miller 1997). BRIDGING provides and expands a teaching-learning community by connecting experts and children from different countries, cultures and backgrounds.

\section{Holistic education aims at:}

1. educating the whole child (body and mind);

2. educating the student as a whole;

3. seeing the student as part of a whole (i.e. of the society, humanity, the environment) (Majethiya, Patel 2015). 
Students, educators and other professionals in the BRIDGING project create a small community, that is a whole, well-functioning organism.

Within the projects several activities are being undertaken based on an action-research design methodology. Project partners take part in several project phases, such as: "Initial Exploration of the City", "Sharing children's ideas about the other" and "Our European City: Expo". Children and teachers (caregivers) in collaboration with cultural and academic institutions are exploring their closest neighbourhood, discussing the meaning of being a citizen of their own city, country and Europe, preparing works of art and visual representations inspired by exploration of the topic. They have an opportunity to share their ideas with other partner countries through: ICT tools (the Facebook page of the project, eTwinning), videos, pictures, sending parcels with gifts, etc. The adults also take part in four training meetings, one in each partner country. Each training meeting lasts five days and includes discussion (in bigger and smaller groups) on what has been done so far, sharing pictures and videos of the children's working process, working on a shared idea of the next steps of the project, exploration of the visited city, etc. The idea for this kind of collaboration was established on the concept that teachers' learning should only be constructed in close links between their educational practices and theory. In that way BRIDGING creates many opportunities for educators for exchanging experiences and reflection that comes from the process of work with children (Teaching Council of Ireland 2016). Therefore, the project focuses on experiences within a pedagogical framework and a particular context (country specific and European). The final result of the project actions is an exhibition of children's works in Portugal, May 2020. At the end of the project there will be prepared a graphic edition of chosen actions of children and adults, which will depict the process of working, artistic expression and final works of art prepared by the children in cooperation with adults.

\section{Preliminary results}

Studies presented in this article were conducted in 2019 in the four countries taking part in the BRIDGING project after first phase of the project. What we present here is the Polish part of the research. The object of the analyses is to investigate how the project is perceived by its main actors: kindergarten teachers. These are not only their preferences according to the project that are examined. We also wanted to learn about the level of their self-efficacy since we perceive both areas are strongly connected. To get an insight into the opinions of teachers and caregivers actively involved in the BRIDGING project, the researchers from the Faculty of Education, University of Warsaw in collaboration with other three BRIDGING academic partners prepared a satisfaction questionnaire. In Poland the form was filled in by a group of 16 kindergarten teachers.

At first, the respondents were asked to what extent their professional experience involves working with different groups of children. As already mentioned, the project concerns the subject of identity and inclusion, that is why the following question was included 
in the questionnaire. There were three different groups of children presented, the results are shown in Figure $1^{2}$.

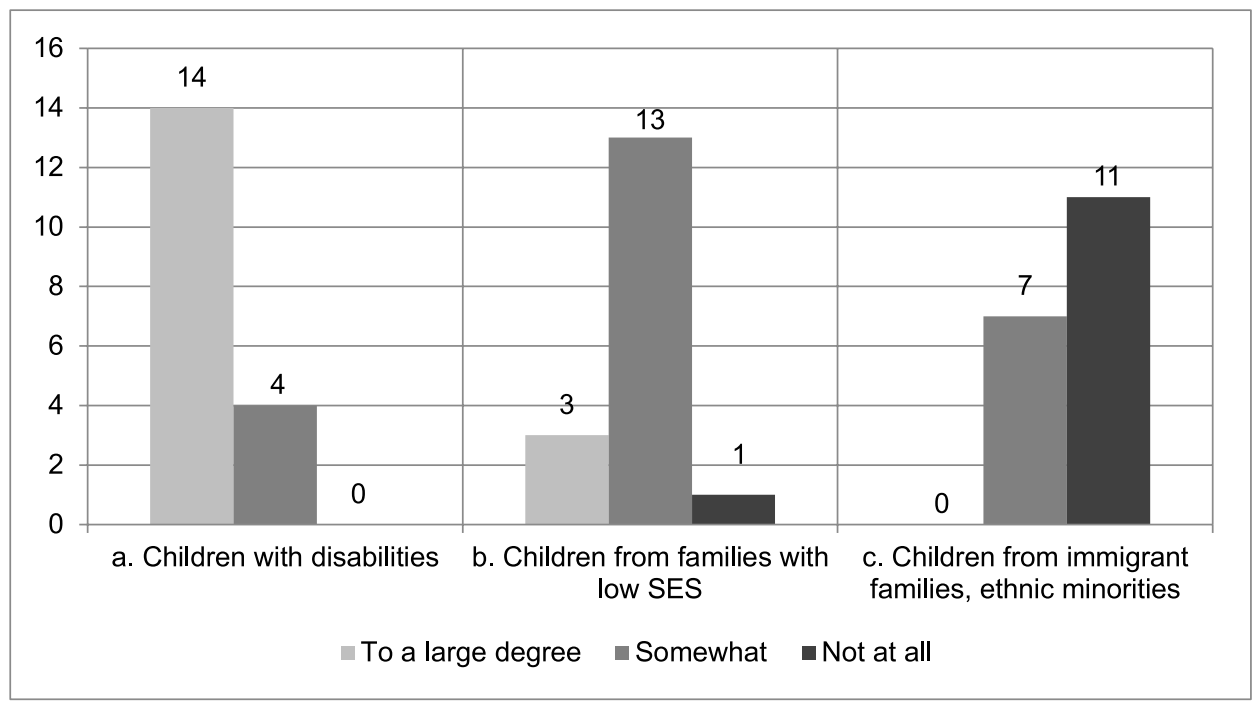

Figure 1. To what extent does your professional experience (considering your entire career in ECEC sector) involve working with different groups of children?

Source: own research.

It might seem obvious that teachers declared they have experience in working with disabled children, as the institution chosen to take part in the research is an integrated type of kindergarten. According to Komorowska, there is also a strong correlation between raising a disabled child and a low socioeconomic status of the family (Komorowska 2017). That might be the reason why teachers chose these two groups of children as the best recognizable by them. Another specific feature of Polish educational establishments is quite a low percentage of children from immigrant families according to other European partner countries, therefore this answer was chosen by the teachers least often.

The results shown in Figure 2 confirms previous suppositions. Teachers working in the integrated kindergarten have a strong sense of self-efficacy in supporting families with disabled children and experiencing financial deficiencies. However, the crucial part of holistic education is also special care for pupils from immigrant families and respondents seem to feel not very confident in that area.

The next step of our analysis directly concerned the respondents' opinions on the BRIDGING project and its influence on their work. Most of them declared that it is the first time they have had an opportunity to take part in that type of professional engage-

2 All figures presented in the following article are graphic representation of respondents answers. 
ment (10 out of 14 respondents). Teachers were asked also about the amount of time they devote to the project actions per week and Figure 3 shows the distribution of results for that question.

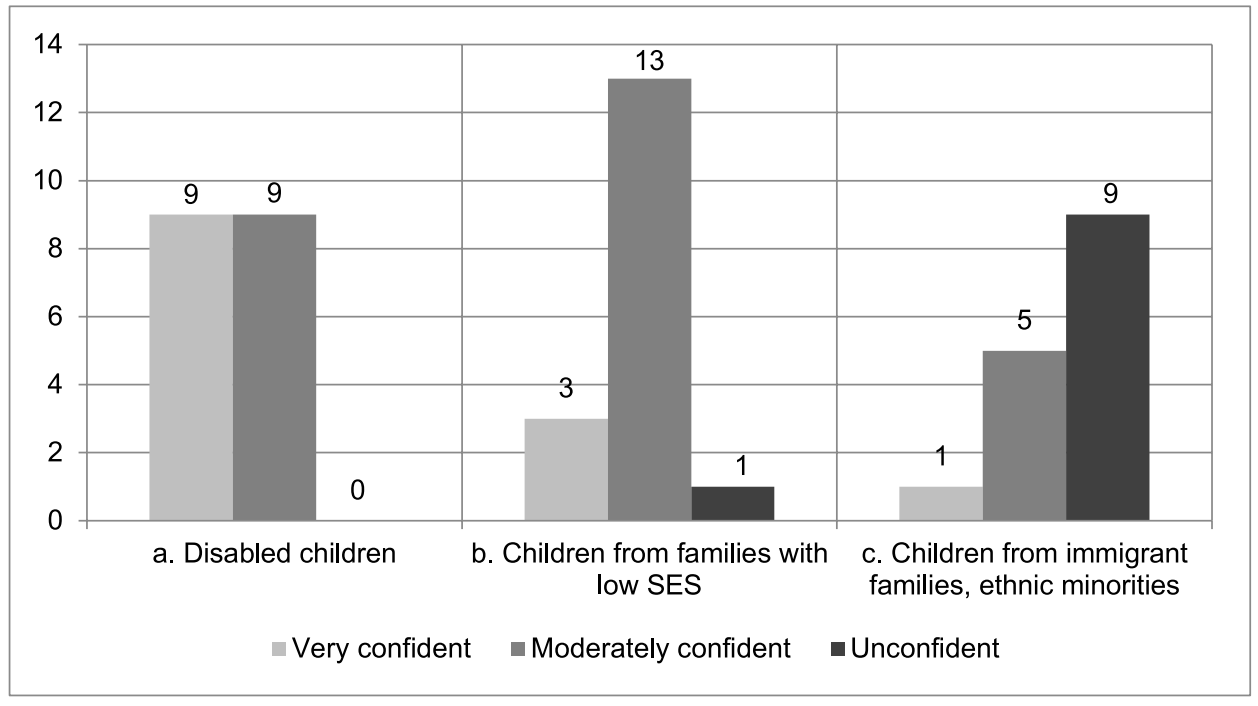

Figure 2. How confident do you feel working with different groups of children?

Source: own research.

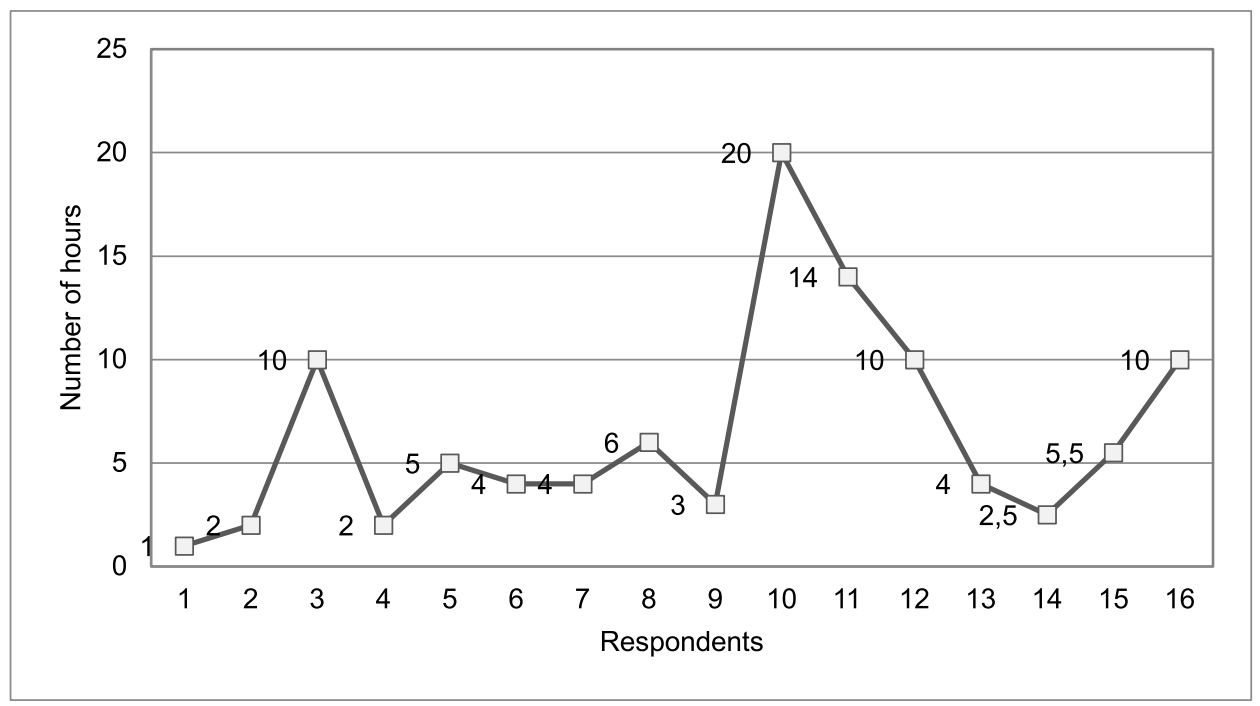

Figure 3. How many hours on average have you spent on the project actions per week?

Source: own research. 
On average, teachers spend 5.6 hours on the project activities weekly. In accordance with the number of kindergarten teachers' working hours ( $25 \mathrm{~h}$ per week), it allows us to presume that they perceive the BRIDGING project as vital for their professional development.

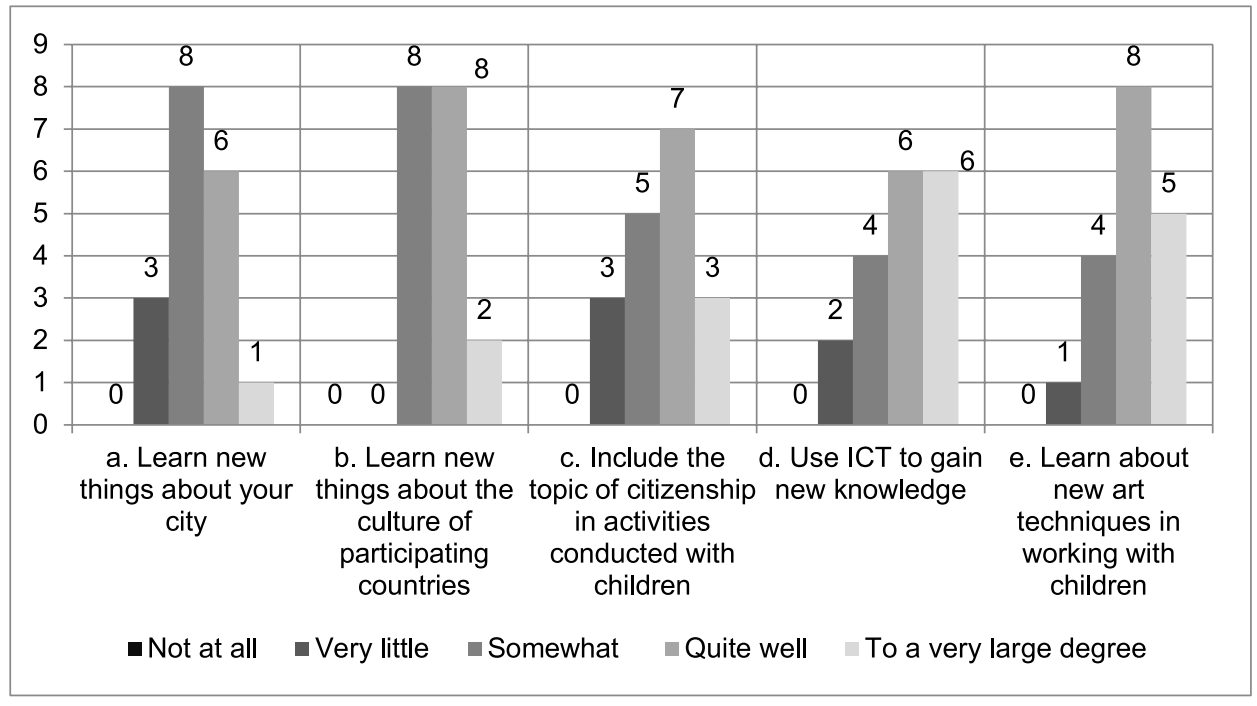

Figure 4. To what extent has involvement in the project encouraged you to undertake the following activities?

Source: own research.

It is noteworthy that a minor number of interviewees have chosen marginal answers for most questions (Fig. 4). We could treat it only as a consequence of the central tendency effect, if not taking the fourth question results into consideration. Teachers claim that they have used ICT to gain new knowledge according to the project. That outcome cannot be overestimated at a time when digital skills are treated as key abilities in the teaching profession (Ansari, Malik 2013).

Moreover, we can state that respondents have learnt a lot in the area of citizenship (questions 1-3, Fig. 4), which was the most crucial issue in the BRIDGING project. They have had many opportunities to gather such knowledge and experience during training meetings in the partner countries and also working with children on the project.

In the opinion of the teachers examined, youngsters who were involved in the project activities with them have had a chance to develop their skills (Fig. 5).

However, teachers perceive their own benefits in a way other than children's achievements. A basic analysis of the respondents' answers for that question (Fig. 5) showed that they chose two marginal answers ("quite well", "to a very large degree") more often than in the case of describing their own results of the project. In general, it can be said that interviewees value the children's results higher than their personal ones. 


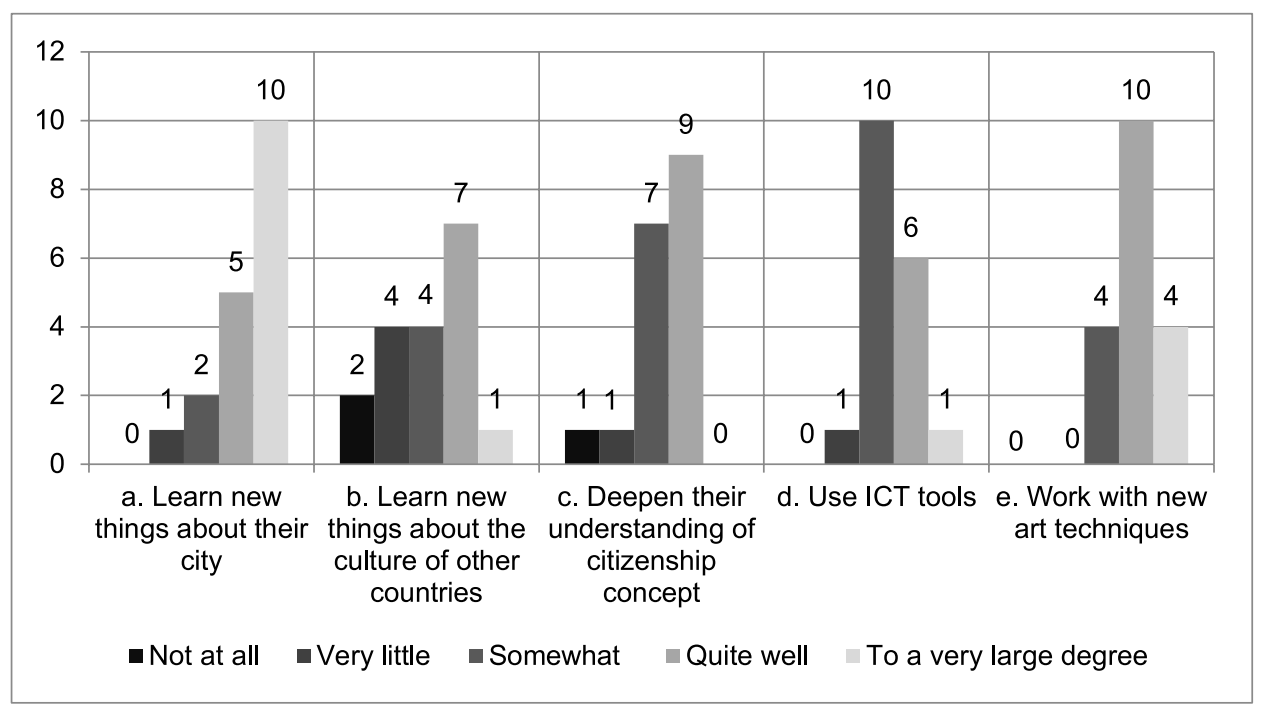

Figure 5. In your opinion, to what extent did children have an opportunity to learn the following things?

Source: own research.

Regarding the respondents' opinions, children have learnt more about the city and citizenship concept than they have. We can assume that the difference is a result of the teachers' perception of their professional role - the child and its development is perceived as the most important in their vocational engagement. Besides, in the adults' views, they already have extensive knowledge on the subject. As far as their own city is concerned, teachers' answers seem justified. According to the research, civic awareness and Poles' knowledge about the European Union is still not vast enough (Maciejewska-Mieszchowska 2017).

In the final stage of research the respondents had an opportunity to reveal what they consider to be the most valuable aspect of the project for their own personal growth. It was an open question and, in general, the teachers' responses focused on the following topics:

- travel, possibilities of exchanging experiences with other teachers from different countries;

- the experiences of work directly with children on themes connected with the city and the country;

- cooperation with other teachers from own setting;

- exploration of the neighbourhood, city;

- an impulse to search for new ideas;

- using modern technologies for gathering new knowledge and learning the new art techniques.

Teachers perceive the BRIDGING project as an opportunity to acquire knowledge about their city, neighbourhood and partners' countries. In their opinion the project has 
improved their skills of using ICT tools and working with various art techniques. Additionally, the respondents had a chance to develop their social skills such as cooperation with children, co-workers and also with colleague teachers from other countries.

\section{Conclusions}

Polish teachers perceive the BRIDGING project as a valuable experience for themselves and also for the kindergarten children. They have declared an increase in their personal knowledge in the area of citizenship. However, that growth concerned experiences connected with their own city, country and information about the partners' habitats. It would be expected that the European project would also enrich their skills of working with children from immigrant families. We consider that result as a crucial indicator for further work with Polish teachers. The undertaken analyzes will be continued. We are going to repeat the survey with the educators in Poland at the end of the project. Our intention is also to compare Polish results with the results of the Bridging partners.

The BRIDGING project finishes in August 2020. By the end of it the researchers expect that the goal of the project, which is improving the quality of the practices for the participants, will have been met. Teachers taking part in BRIDGING project see it as an opportunity to gain more knowledge and experience in working with other professionals from their own country partners and foreign countries institutions. The results of BRIDGING will be disseminated on the project's Facebook profile: facebook.com/bridgingplus/ and in a graphic edition that will be published at the end of the project. The researchers hope that BRIDGING will be an inspiration for other teachers and caregivers and that the improvement of the quality of educational practices in terms of citizenship and holistic approach perceived as being a part of the whole community will continue to spread.

\section{References}

Ansari U., Malik S.K. (2013), Image of an effective teacher in $21^{\text {st }}$ century classroom. "Journal of Educational and Instructional Studies in the World", 3(4).

Bove C., Jensen B., Wysłowska O., Iannone R.L., Mantovani S., Karwowska-Struczyk M. (2018), How does innovative continuous professional development (CPD) operate in the ECEC sector? Insights from a cross-analysis of cases in Denmark, Italy and Poland. "European Journal of Education", DOI: 10.1111/ejed.12262.

Darling-Hammond L., Flook L., Cook-Harvey C., Barron B., Osher D. (2019), Implications for educational practice of the science of learning and development. "Applied Developmental Science", DOI: 10.1080/10888691.2018.1537791.

De Rond M. (2014), The structure of serendipity. "Culture and Organisation”, 20(5).

Komorowska O. (2017), Sytuacja dochodowa rodzin wychowujacych dziecko z niepetnosprawnościa. Wrocław, Wydawnictwo Uniwersytetu Wrocławskiego.

Maciejewska-Mieszchowska K. (2017), Stosunek Polaków do Unii Europejskiej a ich udziat w wyborach do Parlamentu Europejskiego. "Studia Wyborcze", 24. 
Majethiya H., Patel J. (2015), What holistic education claims about present scenario in education? "Recent Thoughts", 6.

Miller R. (1997), What Are Schools For? Holistic Education in American Culture. Brandon, VT, Holistic Education Press.

Teaching Council of Ireland (2016), Cosán: Framework for teachers'learning. Dublin, TCI. https:// www.teachingcouncil.ie/en/Publications/Teacher-Education/Cosan-Framework-for-TeachersLearning.pdf, 10.03.2020.

\section{Online resources}

Citizenship, https://www.britannica.com/topic/citizenship, 10.03.2020.

Eurostat (2019), Statystyki dotyczace migracji i populacji migrantów, https://ec.europa.eu/eurostat/statistics-explained/index.php?title=Migration_and_migrant_population_statistics/pl, 10.03.2020. 